\title{
CORELATION BETWEEN THE PROFESSIONAL COMPETENCE OF TEACHER GUIDANCE AND COUNSELING WITH PERFORMANCE GUIDANCE COUNSELING SERVICE AT SMA NEGERI IN METRO CITY
}

\author{
Nurul Atieka \& Rina Kurniawati \\ Program Studi Bimbingan dan Konseling UM Metro
}

\begin{abstract}
Many of the problems related to the implementation of guidance and counseling services. Variable allegedly linked to the issue of counseling services is the professional competence of teachers BK. This study aims to determine the relationship between the professional competence of teachers guidance and counseling to the implementation of guidance and counseling services in SMA as the city Metro. Correlational research approach. The population in this study are all guidance and counseling teacher in SMA as the city Metro and there are 17 teachers guidance and counseling. the total sample. The instrument used was a questionnaire. Data analysis techniques use Product Moment formula. With the results obtained with the 0.57 significance level of $5 \%$ $=0.514$. The conclusion of this study were: 1) the professional competence of teachers guidance and counseling are in the high category, 2) the implementation of guidance and counseling services are in high category, 3) there is a relationship between the professional competence of teachers guidance and counseling to the implementation of guidance and counseling services.
\end{abstract}

Keyword: professional competence, Guidance and Counseling Services.

\section{PENDAHULUAN}

Bimbingan dan
merupakan bagian integral dari
pendidikan nasional. Pendidikan
nasional bertujuan untuk membentuk
individu yang memiliki kepribadian
yang utuh, yang berakhlak mulia,
kreatif dan mandiri. Untuk mewujudkan
tujuan pendidikan nasional dalam
membentuk kepribadian individu
tersebut bimbingan dan konseling

sangat dibutuhkan dalam tecapainya tujuan pendidikan tersebut.

$$
\text { Bimbingan dan Konseling }
$$
memegang peranan yang sangat penting dalam menunjang keberhasilan tugas perkembangan. Menurut Prayitno dan Erman Amti ( 2004)

Bimbingan adalah proses
pemberian bantuan yang
dilakukan oleh orang yang ahli
kepada seseorang atau beberapa
orang anak, baik anak-anak,
remaja, maupun dewasa, agar
orang-orang yang dibimbing
dapat mengembangkan


kemampuan dirinya sendiri dan mandiri dengan memanfaatkan kekuatan anak dan sarana yang ada dan dapat dikembangkan berdasarkan norma-norma yang berlaku.

Menurut Tolbert (dalam Prayitno dan Erman Amti, 2004)

Konseling adalah proses pemberian bantuan yang dilakukan melalui kontak langsung/wawancara konseling antara dua orang oleh konselor kepada konseli yang mengalami permasalahan agar konseli dapat memecahkan permasalahan yang dihadapi sehingga dapat mengembangkan potensi yang dimiliki secara optimal.

Dengan demikian bimbingan dan konseling merupakan suatu proses pemberian bantuan yang dilakukan oleh konselor melalui wawancara konseling kepada konseli agar dapat mengembangkan kemampuan untuk memecahkan permasalahan yang dialami dan mengembangkan segala potensi secara optimal berdasarkan norma-norma yang berlaku.

Tugas guru bimbingan dan konseling sangatlah dibutuhkan dalam tercapainya pelaksanaan bimbingan dan konseling yang baik. Tetapi, pada kenyataanya pelaksanaan layanan bimbingan dan konseling masih belum dapat berjalan sesuai dengan apa yang diharapkan.
Berdasarkan hasil pra-survei yang dilakukan di salah satu SMA Negeri di Kota Metro melalui wawancara dengan guru bimbingan dan konseling terkait dengan pelaksanaan pelayanan bimbingan dan konseling menunjukkan pelaksanaan konseling individu yang belum terlaksana secara optimal. Seharusnya konseling individu terjadi atas dasar sukarela selama ini layanan konseling individu dapat terlaksana apabila guru bimbingan dan konseling sudah mengetahui permasalahan tersebut sebelumnya kemudian guru bimbingan dan konseling memanggil siswa yang sedang bermasalah, bukan dari kesukarelaan siswa tersebut datang kepada guru bimbingan dan konseling dalam upaya untuk memecahkan masalahnya. Dengan kata lain, siswa cenderung enggan untuk berhubungan dengan guru bimbingan dan konseling.

Permasalahan tentang masih belum optimalnya pelaksanaan layanan bimbingan dan konseling dapat dilihat oleh beberapa variabel, seperti: 1) Waktu Pelaksanaan layanan, 2) Sarana dan prasarana yang kurang mendukung, 3) Administrasi kurang memadahi, dan 4) Kompetensi guru bk. Dari beberapa variabel yang mempengaruhi diduga kompetensi memiliki pengaruh terhadap 
pelaksanaan layanan bk. Menurut Sagala (2009: ) mendefinisikan kompetensi merupakan peleburan dari pengetahuan (daya pikir), sikap (daya Kalbu), dan keterampilan (daya fisik) yang diwujudkan dalam bentuk perbuatan. Pendapat tersebut menekankan bahwa segenap kemampuan tersebut harus diwujudkan atau diterapkan dalam suatu aktifitas atau kegiatan. Kompetensi profesional merupakan pilar yang sangat besar kontribusinya dalam menunjang keberhasilan pelayanan konseling. Ciri ciri konselor yang memiliki kompetensi seperti yang diungkapkan oleh Moh. Surya (2003), yaitu (1) secara berkelanjutan meningkatkan pengetahuan tentang perilaku dan pelayanan konseling, antara lain melalui bacaan, menghadiri konferensi atau seminar, mengikuti pelatihan dan berdiskusi dengan teman sejawat, (2) memiliki pengalaman hidup yang dapat membantu konselor dalam meningkatkan kompetensi dan mempertajam keterampilannya, (3) memiliki berbagai gagasan dan pendekatan dalam konseling, dan (4) melakukan penilaian dalam setiap langkah konseling untuk mancapai keefektifan konseling.
Kompetensi profesional dalam Peraturan Menteri Pendidikan Nasional Nomor 27 Tahun 2008 mencakup seorang guru Bimbingan dan Konseling yang menguasai konsep dan praksis asesmen untuk memahami kondisi kebutuhan, dan masalah konseli; menguasai kerangka teoritik dan praksis bimbingan dan konseling; merancang program bimbingan dan konseling; mengimplementasikan program bimbingan dan konseling ang komprehensif; menilai proses dan hasil kegiatan bimbingan dan konseling; memiliki kesadaran dan komitment terhadap etika professional; menguasai konsep dan praksis penelitian dalam bimbingan dan konseling. Penguasaan yang untuh dari kompetensi profesional guru BK mencerminkan profesionalitas dari profesi yang disandang oleh guru BK itu sendiri. Sehingga adanya permasalahan yang muncul dalam pelaksanaan bimbingan dan konseling disekolah diduga salahs atu varabel yang mempengaruhinya adalah kompetensi profesional guru BK.

Berangkat dari masalah yang ditemukan serta dukungan teori tentang kompetensi profesional dan pelaksanaan layanan BK, maka masalah penelitian dirumuskan adalah "Apakah ada 
hubungan antara kompetensi profesional guru bimbingan dan konseling dengan pelaksanaan layanan bimbingan dan konseling di SMA Negeri se-Kota Metro?"

Tujuan penelitian adalah ingin mengetahui hubungan antara kompetensi profesional guru bimbingan dan konseling dengan pelaksanaan layanan bimbingan dan konseling di SMA Negeri se-Kota Metro.

\section{METODE PENELITIAN}

Penelitian ini menggunakan pendekatan kuantitatif yaitu merupakan penelitian yang menekankan analisisnya pada data-data yang diolah dengan metode statistika . Dengan pendekatan kuantitatif-korelatif, penelitian ini akan diperoleh signifikansi hubungan antar variabel yang diteliti. Populasi penelitian ini adalah seluruh guru bimbingan dan konseling SMA Negeri di Kota Metro. Secara rinci populasi penelitian adalah sebagai berikut:

Tabel 1. Populasi Penelitian

\begin{tabular}{|c|l|c|}
\hline No & \multicolumn{1}{|c|}{ Nama Sekolah } & $\begin{array}{c}\text { Jumlah } \\
\text { Guru BK }\end{array}$ \\
\hline 1 & SMA N 1 Metro & 5 \\
\hline 2 & SMA N 2 Metro & 3 \\
\hline 3 & SMA N 3 Metro & 3 \\
\hline 4 & SMA N 4 Metro & 3 \\
\hline 5 & SMA N 5 Metro & 2 \\
\hline 6 & SMA N 6 Metro & 1 \\
\hline
\end{tabular}

\begin{tabular}{|c|c|}
\hline Jumlah & 17 \\
\hline
\end{tabular}

Teknik pengambilan sampel adalah dengan teknik jenuh, sehingga seluruh populasi penelitian dijadikan sampel penelitian. Instrumen yang digunakan untuk mengumpulkan data adalah skala likert. Teknik analisis data menggunakan kolerasi product moment, (Sugiyono, 2012: 225), yaitu sebagai barikut:

$$
r_{x y}=\frac{\sum x y}{\sqrt{\left(\sum x^{2}\right)\left(\sum y^{2}\right)}}
$$

Keterangan:

rxy = Angka indeks korelasi

"r"Product moment

$\mathrm{n} \quad=$ Number of cases

Selanjutnya harga $r_{x y}$ kemudian dikonsultasikan dengan harga $r_{\text {tabel }}$ untuk mengetahui taraf signifikan sebagai berikut:

$r_{\text {hitung }} \geq r_{\text {tabel }} 5 \%$ maka sangat signifikan, Ha diterima.

$\mathrm{r}_{\text {hitung }} \leq \mathrm{r}_{\text {tabel }} 5 \%$ maka Ha ditolak.

\section{HASIL}

\section{A. Deskripsi Data Kompetensi Profesional Guru Bimbingan dan Konseling}

Data mengenai kompetensi profesional diperoleh dari penyebaran instrumen terhadap 17 sampel penelitian 
yang sudah diuji validitas dan reliabilitasnya. Hasil penyebaran instrumen kemudian ditabulasikan seagai berikut:

Tabel 2. Rekapitulasi Perhitungan Kompetensi Profesional

\begin{tabular}{|c|c|c|c|c|c|}
\hline $\begin{array}{l}\mathbf{N} \\
\mathbf{0}\end{array}$ & $\begin{array}{c}\text { Kode } \\
\text { Sampel }\end{array}$ & Skor & No & $\begin{array}{c}\text { Kode } \\
\text { Sampel } \\
\end{array}$ & Skor \\
\hline 1 & S-01 & 130 & 10 & S-10 & 115 \\
\hline 2 & S-02 & 109 & 11 & S-11 & 116 \\
\hline 3 & S-03 & 112 & 12 & S-12 & 113 \\
\hline 4 & S-04 & 113 & 13 & $\mathrm{~S}-13$ & 117 \\
\hline 5 & S-05 & 112 & 14 & S-14 & 106 \\
\hline 6 & S-06 & 114 & 15 & S-15 & 106 \\
\hline 7 & S-07 & 130 & 16 & S-16 & 106 \\
\hline 8 & S-08 & 111 & 17 & S-17 & 114 \\
\hline 9 & S-09 & 109 & & & \\
\hline \multicolumn{3}{|c|}{ Jumlah } & \multicolumn{2}{|r|}{1933} & \\
\hline \multicolumn{3}{|c|}{$\mathbf{N}$} & \multicolumn{2}{|r|}{17} & \\
\hline \multicolumn{3}{|c|}{ Skor Tertinggi } & \multicolumn{2}{|r|}{130} & \\
\hline \multicolumn{3}{|c|}{ Skor Terendah } & \multicolumn{2}{|r|}{106} & \\
\hline
\end{tabular}

Berdasarkan analisis yang dilakukan pada data kompetensi profesional guru bimbingan dan konseling yang diperoleh dengan sebanyak $(\mathrm{N})=17$, diketahui bahwa variabel kompetensi profesional guru bimbingan dan konseling memiliki Mean $=114,02$ Standar Deviasi $=63,02$ , Median $=113$, Modus $=112,17$, Nilai Maksimum $=130$ dan Nilai Minimum = 106. Untuk identitas kecenderungan tinggi rendahnya skor variabel pada kompetensi profesional guru bimbingan dan konseling ditetapkan berdasarkan pada kriteria ideal, yaitu : menggunakan nilai Mean Ideal $=90$, Nilai Maksimum Ideal $=150$ dan Nilai Minimum Ideal = 30 , SD Ideal $=20$ yang diketahui dari perkalian jumlah soal pada skala kompetensi profesional dengan skala pemberian skor tertinggi dan terendah pada kompetensi profesional

Berdasarkan data yang diperoleh akan dilakukan pengkategorisasian skor kompetensi profesional guru bimbingan dan konseling berdasarkan distribusi normal. Peneliti menggolongkan subjek ke dalam 3 kategorisasi. Norma kategorisasi berdasarkan mean ideal disajikan dalam tabel berikut:

Tabel 3. Pengkategorian Kompetensi Profesional

\begin{tabular}{|c|c|}
\hline Interval Nilai & Kategori \\
\hline $\mathrm{X}<(\mathrm{Mi}-1,0 \mathrm{Sdi})$ & Rendah \\
\hline $\begin{array}{c}(\mathrm{Mi}-1,0 \mathrm{Sdi}) \leq \mathrm{X}< \\
(\mathrm{Mi}+1,0 \mathrm{Sdi})\end{array}$ & Sedang \\
\hline$(\mathrm{Mi}+1,0 \mathrm{Sdi}) \leq \mathrm{X}$ & Tinggi \\
\hline
\end{tabular}

Berdasarkan kategorisasi di atas, maka gambaran kompetensi guru BK SMA N di Kota Metro adalah dilihat pada tabel sebagai berikut :

Tabel 3. Deskripsi Kompetensi Profesional Guru BK SMA N Se-Metro

\begin{tabular}{|c|c|c|l|}
\hline Kategori & Interval & F & $\%$ \\
\hline Rendah & $\mathrm{X}<70$ & 0 & $0 \%$ \\
\hline
\end{tabular}




\begin{tabular}{|c|c|c|c|}
\hline Sedang & $\begin{array}{c}70 \leq \mathrm{X} \\
<110\end{array}$ & 5 & $29,42 \%$ \\
\hline Tinggi & $110 \leq \mathrm{X}$ & 12 & $70,58 \%$ \\
\hline
\end{tabular}

\section{B. Deskripsi}

Layanan

Data Pelaksanaan

Konseling

Data mengenai pelaksanaan layanan bimbingan dan konseling diperoleh dari penyebaran instrumen terhadap 17 sampel penelitian yang sudah diuji validitas dan reliabilitasnya. Hasil penyebaran instrumen kemudian ditabulasikan. Berikut hasil rekapitulasi skala pelaksanaan layanan BK yang telah diberikan kepada guru Bimbingan dan konseling.

Tabel 4. . Rekapitulasi Skor

$$
\text { Pelaksanaan Layanan BK }
$$

\begin{tabular}{|c|c|c|c|c|c|}
\hline $\mathbf{N}$ & Kode & Skor & $\mathbf{N}$ & Kode & Skor \\
o & Sampel & & o & Sampel & \\
\hline 1 & S-01 & 60 & 10 & S-10 & 54 \\
\hline 2 & S-02 & 54 & 11 & S-11 & 57 \\
\hline 3 & S-03 & 54 & 12 & S-12 & 55 \\
\hline 4 & S-04 & 55 & 13 & S-13 & 64 \\
\hline 5 & S-05 & 51 & 14 & S-14 & 55 \\
\hline 6 & S-06 & 53 & 15 & S-15 & 54 \\
\hline 7 & S-07 & 58 & 16 & S-16 & 55 \\
\hline 8 & S-08 & 55 & 17 & S-17 & 55 \\
\hline 9 & S-09 & 45 & & & \\
\hline \multicolumn{7}{|c|}{ Jumlah } & & $\mathbf{9 3 0}$ \\
\hline N & & 17 \\
\hline & Skor Tertinggi & & \\
\hline & Skor Terendah & & $\mathbf{4 5}$ \\
\hline
\end{tabular}

Berdasarkan analisis yang dilakukan pada data pelaksanaan layanan yang diperoleh dengan sebanyak $(\mathrm{N})=17$, diketahui skor pelaksanaan konseling memiliki Mean = 54,99, Standar Deviasi $=3,43$, Median= 51,95, Modus $=54,72$ Nilai Maksimum $=64$ dan Nilai Minimum $=45$

Untuk identitas kecenderungan tinggi rendahnya skor variabel pada pelaksanaan layanan bimbingan dan konseling ditetapkan berdasarkan pada kriteria ideal, yaitu : menggunakan nilai Mean Ideal $=43,5$, Nilai Maksimum Ideal $=75$ dan Nilai Minimum Ideal $=$ 15 , SD Ideal $=10$ yang diketahui dari perkalian jumlah soal pada plaksanaan layanan bimbingan dan konseling dengan skala pemberian skor tertinggi dan terendah pada palaksanaan layanan bimbingan dan konseling

Berdasarkan data yang diperoleh akan dilakukan pengkategorisasian pelaksanaan layanan bimbingan dan konseling berdasarkan distribusi normal. Peneliti menggolongkan subjek kedalam 3 kategorisasi. Norma kategorisasi berdasarkan mean ideal disajikan dalam tabel berikut:

Tabel 5. deskripsi Skor Palayanan BK 


\begin{tabular}{|c|c|}
\hline Interval Nilai & Kategorisasi \\
\hline $\mathrm{X}<33,5$ & Rendah \\
\hline $33,5 \leq \mathrm{X}<53,5$ & Sedang \\
\hline $53,5 \leq \mathrm{X}$ & Tinggi \\
\hline
\end{tabular}

Berdasarkan nilai pelaksanaan layanan bimbingan dan konseling di atas dapat diketahui tidak ada seorang pun berada dalam kategori rendah, 3 orang berada dalam kategori sedang $(17,65 \%)$ dan 14 orang berada dalam kategori tinggi $(82,35, \%)$. Kategori proporsi variabel ini dapat dilihat pada tabel sebagai berikut :

Tabel 6 Proporsi Pelaksanaan Layanan

\begin{tabular}{|c|c|c|c|}
\hline Kategori & Interval & $\mathbf{F}$ & $\%$ \\
\hline Rendah & $\begin{array}{l}X< \\
33,5\end{array}$ & 0 & $0 \%$ \\
\hline Sedang & $\begin{array}{c}33,5 \leq \\
X< \\
53,5\end{array}$ & 3 & $17,65 \%$ \\
\hline Tinggi & $\begin{array}{c}53,5 \leq \\
X\end{array}$ & 14 & $82,35, \%$ \\
\hline
\end{tabular}

\section{Pengujian Hipotesis}

Analisis ini dimaksudkan untuk mengolah data yang telah terkumpul, baik dalam variabel kometensi profesional maupun variabel pelaksanaan layanan bimbingan dan konseling yang bertujuan unuk membuktikan diterima atau ditolaknya hipotesis yang diajukan penulis dengan menggunakan analisis statistik korelasi product moment.

Interpretasi terhadap angka indeks koefisien korelasi dengan cara dikonsultasikan dengan tabel nilai " $r$ " Product moment,

Dengan mengetahui tabel kerja koefisien korelasi antara variabel $\mathrm{X}$ dan Y maka selanjutnya mencari nilai koefisien korelasi dengan rumus sebagai berikut:

$$
\begin{aligned}
& r_{x y}=\frac{\sum x y}{\sqrt{\left(\sum x^{2}\right)\left(\sum y^{2}\right)}} \\
& r_{x y}=\frac{217,53}{\sqrt{(785,53)(185,53)}}=\frac{217,53}{\sqrt{145739,38}}= \\
& \frac{217,53}{381,75828}=0,5698108=0,57
\end{aligned}
$$

Dari hasil perhitungan di atas, didapatkan nilai indeks korelasi sebesar 0,57 . Jika dikonsultasika pada tabel interpretasi data diatas, angka " $\mathrm{r}$ " sebesar $(0,57)$ yang berada antara rentang nilai 0,40 - 0,70 termasuk dalam kategori yang tergolong sedang.

Untuk mengetahui taraf signifikansi $\mathrm{r}_{\mathrm{xy}}$ melalui tabel nilai " $\mathrm{r}$ " Product moment, dengan menghitung 
derajad bebas ( $\mathrm{db}$ ) atau degree of freedom (df) terlebih dahulu yaitu:

$\mathbf{D f}=\mathbf{N}-\mathbf{n r}$

Dalam penelitian ini dapat diketahui bahwa:

$\mathrm{N}=17, \mathrm{nr}=2$

$\mathrm{Df}=50-2=15$

Setelah diketahui nilai df maka selanjutnya dikonsultasikan dengan tabel nilai "r" Product moment pada taraf signifikan 5\%. Dengan df $=\mathrm{n}-2=$ 15 pada taraf signifikansi 5\%, diperoleh $r_{\text {tabel }}$ sebesar 0,514. Maka $r_{\text {hitung }}>r_{\text {tabel }}$ atau 0,57>0,514, maka Ho ditolak dan Ha diterima. Jadi ada hubungan antara kompetensi profesional guru bimbingan dan konseling dengan pelaksanaan layanan bimbingan dan konseling di SMA Negeri se-Kota Metro.

Setelah uji hipotesis dilakukan, untuk mengetahui seberapa besar hubungan antara vaiabel $\mathrm{X}$ dan variabel Y, maka dihitung suatu koefisien penentu (coefficient of determination) dengan rumus sebagai berikut:

$\mathrm{KD}=\mathbf{r}^{2} \times 100 \%$

$$
\mathbf{r}_{\mathrm{xy}}=0,57
$$

$$
\mathrm{KD}=\mathbf{0 , 5 7 ^ { 2 } \times 1 0 0}
$$

$$
=0,3249 \times 100
$$

$=32,49 \%$

Kompetensi profesional guru bimbingan dan konseling (X) memberikan konstribusi terhadap pelaksanaan layanan bimbingan dan konseling di SMA Negeri se-Kota Metro sebesar 32,49\% dan $67,51 \%$ lainnya berasal dari variabel lain.

\section{PEMBAHASAN}

Berdasarkan hasil perhitungan analisis penelitian korelasi antara kompetensi profesional guru bimbingan dan konseling dengan pelaksanaan layanan bimbingan dan konseling yang telah dilakukan untuk kompetensi profesional guru bimbingan dan konseling dapat disimpulkan kompetensi profesional guru bimbingan dan konseling dapat dinilai sangat baik hal tersebut dapat dilihat dari tidak ada seorang pun guru Bimbingan dan 
konseling di SMA Negeri se-Kota Metro berada dalam kategori sangat rendah, 5 orang berada dalam kategori sedang $(29,42 \%), 12$ orang berada dalam kategori tinggi $(70,58 \%)$. Begitu juga dengan pelaksanaan layanan bimbingan dan konseling dapat dilaksanakan secara baik oleh guru bimbingan dan konseling di SMA Negeri se-Kota Metro, hal tersebut dapat dilihat dari tidak adanya seorang pun berada dalam kategori rendah, 3 orang berada dalam kategori sedang $(17,65 \%)$ dan 14 orang berada dalam kategori tinggi $(82,35, \%)$.

Berdasarkan hasil perhitungan analisis penelitian korelasi antara kompetensi profesional guru bimbingan dan konseling dengan pelaksanaan layanan bimbingan dan konseling yang telah dilakukan dengan menggunakan rumus Korelasi Product Moment diperoleh $r_{\text {hitung }}$ sebesar 0,57 dan $r_{\text {tabel }}$ dengan $\mathrm{n}-2=15$ pada taraf signifikan $5 \%$ yaitu sebesar 0514 . Karena $\mathrm{r}_{\text {hitung }}>$ $r_{\text {tabel }}$ atau 0,57>0,514. Maka nilai koefisien yang positif menunjukkan bahwa hubungan antara kompetensi profesional guru bimbingan dan konseling dengan pelaksanaan layanan bimbingan dan konseling searah. Hal ini berarti hipotesis yang diajukan yaitu ada hubungan antara kompetensi profesional guru bimbingan dan konseling dengan pelaksanaan layanan bimbingaan dan konseling di SMA Negeri se-Kota Metro, diterima. Artinya, jika pelaksanaan layanan bimbingan dan konseling itu tinggi maka kompetensi profesional guru bimbingan dan konseling juga harus tinggi, jadi apabila kompetensi pofesional guru bimbingan dan konseling itu baik maka pelaksanaan layanan bimbingan dan konseling juga baik.

Selain itu pula analisis dari hasil perhitungan Kompetensi profesional guru bimbingan dan konseling (X) memberikan konstribusi terhadap pelaksanaan layanan bimbingan dan konseling di SMA Negeri se-Kota Metro sebesar $32,49 \%$ dan $67,51 \%$ lainnya berasal dari variabel lain.

\section{KESIMPULAN DAN SARAN}

\section{Kesimpulan}

Berdasarkan hasil penelitian dan pembahasan mengenai hubungan antara kompetensi profesional guru bimbingan dan konseling dengan pelaksanaan layanan bimbingan dan konseling di SMA Negeri se-Kota Metro dapat disimpulkan bahwa kompetensi 
profesional dan pelaksanaan layanan yang dilakukan sudah cukup baik hal ini dilihat dari:

1. Kompetensi professional guru bimbingan dan konseling berada dalam katagori tinggi, hal ini menunjukkan bahwa kompetensi yang dimiliki oleh guru bimbingan dan konseling di SMA Negeri seKota Metro baik. Ha diterima.

2. Pelaksanaan layanan bimbingan dan konseling berada dalam katagori tinggi, hal ini menunjukkan bahwa pelaksanaan layanan bimbingan dan konseling di SMA Negeri se-Kota Metro baik. Ha ditolak.

3. Antara kompetensi guru bimbingan dan konseling dengan pelaksanaan layanan bimbingan dan konseling menunjukkan nilai koefisien yang positif sehingga dapat disimpulkan bahwa ada hubungan antara kompetensi professional guru bimbingan dan konseling dengan pelaksanaan layanan bimbingan dan konseling.

\section{Saran.}

Berdasarkan hasil penelitian dan kesimpulan yang telah dikemukakan di atas maka dapat diajukan beberapa saran yang dapat bermanfaat, diantaranya sebagai berikut:

1. Bagi guru bimbingan dan konseling, agar lebih meningkatkan kemampuan profesionalnya.

2. Bagi pihak sekolah dapat mendukung pelaksanaan program bimbingan dan konseling yang dijalankan oleh guru BK, serta saling bekerjasama berupaya untuk meningkatkan kualitas layanan bimbingan dan konseling.

3. Bagi peneliti selanjutnya agar bisa mengembangkan penelitian mengenai Kompetensi profesional.

\section{DAFTAR PUSTAKA}

Moh. Surya. 2003. Psikologi Konseling. Bandung : Pustaka Bany Quraisy

Peraturan Mentri Pendidikan Nasional Republik Indonesia Nomor 27 Tahun 2008 Tentang Standar Kualifikasi Akademik dan Kompetensi Konselor

Prayitno dan Erman Amti. 2004. DasarDasar Bimbingan dan Konseling. Jakarta : Rineka Cipta.

Sugiyono.2012. Metode Penelitian Kualitatif, Kuantitatif, dan $R \& D$. Jakarta: Alfabeta

Syaiful Sagala. 2009. Kemampuan Profesional Guru dan Tenaga kependidikan. Jakarta : Alfabeta. 